\title{
Identification of Entrepreneurial Opportunities in Manufacturing for Bachelor Degree Holding Engineers
}

\author{
Sangarappillai Sivaloganathan*, Khalifa Hamid Hareb, Latifa Ali, Fatima Ali, Maitha Khalfan, Mariam Sultan \\ and Maitha Ali
}

Department of Mechanical Engineering, United Arab Emirates University, United Arab Emirates

Submission: June 02, 2020; Published: July 13, 2020

*Corresponding author: Sangarappillai Sivaloganathan, Department of Mechanical Engineering, United Arab Emirates University, United Arab Emirates

\begin{abstract}
Advanced technologies require less purely manual workers and proportionately more with higher education level. Bachelor's degree holding engineers are able to fill this requirement and establish new, innovative and technologically advanced enterprises. But there is no methodology for the 'Identification of entrepreneurial opportunity' which is the genesis of building an innovative enterprise. This paper proposes 'Trigger' as a methodology to identify entrepreneurial opportunities. It describes the background literature that formed the basis for the 'Trigger' methodology and provides a case study where a group of senior mechanical engineering undergraduates used 'Trigger' to identify the opportunity for a smart water jet service workshop called 'Pilot water jet services for Smart Manufacturing. The paper concludes that 'Trigger' is a correct step in the right direction.
\end{abstract}

Keywords: Entrepreneurial opportunity identification; Elemental constituent characteristics of Entrepreneurial Opportunities; KJ method

\section{Introduction}

Manufacturing Industry is going through a paradigm shift towards advanced technologies with automation and autonomous operations. Advanced technologies require less purely manual workers and proportionately more workers with higher education level. Hicks \& Srikant [1] found that in the US productivity gains caused 87 percent of manufacturing job losses between 2000 and 2010. It is in this scenario the bachelor's degree holding engineers march out of the universities. President Obama [2] once stated that entrepreneurship means ownership and self-determination, as opposed to simply being dependent on somebody else for your livelihood and your future. Yes! The environment is conducive for the graduates to become engineering entrepreneurs. But how do these aspiring graduates can 'Identify Entrepreneurial Opportunities' suitable for their educational background, national condition or circumstance, and personal fulfilment? This paper proposes a systematic methodology called 'Trigger' for the 'Identification of Entrepreneurial Opportunities in Manufacturing for Bachelor Degree Holding Engineers'.

Literature suggests the following in relation to answering this question

\section{Economic Development}

The circular flow model of the economy represents economic activities as flows of money, goods and services, resources etc. between economic agents, such as households and firms, and the flows are in static equilibrium. In this Schumpeterian concept, economic development is defined as a 'Spontaneous and discontinuous change in the channels of flow, a disturbance of equilibrium which forever alters and displaces the equilibrium state previously existing' [3]. To make the circular flow and its static setting, dynamic and consistent with development, changes must take place in the flow system. These changes can be brought through innovations. Innovation may be defined as a change in existing production system to be introduced by the entrepreneur with a view to make profits and reduce costs. Accordingly, for the graduates, changes that are heavily dependent on the theoretical knowledge, must be identified and built.

\section{Entrepreneurial Opportunities}

Identifying the 'Entrepreneurial Opportunities' is the genesis of the innovation process. Entrepreneurial opportunities are those situations in which new goods, services, raw materials, and organizing methods can be introduced and sold at greater than their cost of production $[4,5]$. If the action or system by which a result is achieved is called the 'Means' and the result is called an 'End', entrepreneurial opportunities require the discovery of new 'means-ends' relationships. Looking at the definitions of 
'Entrepreneurial Opportunity' in the literature, there are several of them. For example, another definition states that Entrepreneurial Opportunity is an idea or dream that is discovered or created by an entrepreneurial entity and that is revealed through analysis over time to be potentially lucrative [6]. Davidsson [7] argues that the construct 'Entrepreneurial Opportunity' is confusing and suggests a fundamental re-conceptualization using the constructs External Enablers, New Venture Ideas, and Opportunity Confidence to capture the many important ideas commonly discussed under the 'opportunity' label. Whatever the definition is 'Identifying Entrepreneurial Opportunities utilizing graduate level theoretical knowledge' is a fundamental need for initiating graduate-level enterprises.

\section{Use of Knowledge in Society}

Hayek [8] argues that the economic problem requires the utilization of knowledge not given to anyone in its totality or never existed in its concentrated or integrated form. Instead it is dispersed and possessed by individuals as bits of incomplete and frequently contradicting knowledge. If 'planning' is the making of complex interrelated decisions, the question is how this knowledge bits are communicated to the decision maker and, is it a central person or body as in monopoly or is it several subgroups like in perfect competition. Again, scientific knowledge can be systematically given to graduates but the knowledge about particular circumstances and time, about which practically everyone has some bit that has some advantage over all others, also is needed for initiating an enterprise. Thus, scientific knowledge and knowledge external to scientific knowledge, are needed to develop an economic entity. To ensure the quality and content of undergraduate programs, they are subjected to accreditation process [9] where the attainment of 'Program Learning Outcomes' are ensured. Shamshina [10] enumerates the competences necessary for the bachelor-degree-holding engineer specialising in engineering industries. While a highquality scientific knowledge is fundamental, a systematic method to collect the dispersed knowledge bits is pivotal for triggering a graduate level innovation or enterprise.

\section{Systematic Approach to Identify Entrepreneurial Opportunities}

Du Preez \&Louw [11] argue that enterprises should not wait for the innovation to arrive arbitrarily, but rather proactively plan for innovation. They present a combined convergent and divergent approach for managing innovation. They propose an innovation framework called the 'Fugle model' developed to help businesses to identify, evaluate, develop, implement and exploit new products and services more efficiently and effectively. They state that the model is centered on a generic innovation process that combines the convergent innovation front-end or funnels (identification and evaluation) with the divergent deployment and exploitation of the innovation (termed the innovation bugle). Their model consists of six stages:
a) Idea generation/identification stage
b) concept definition stage
c) concept feasibility and refinement stage
d) deployment stage
e) refinement and formalization stage
f) exploitation stage

Out of these the first two, Idea generation/identification stage and concept definition stage are very much related to the 'Identification of Entrepreneurial Opportunities'. They outline

a) Collect, Categorize and Present Information

b) Generate and Collect Ideas

c) capture ideas and

d) idea filter as the steps for the first stage

The focus of the second stage is to transform the idea into a workable concept. A concept could be developed from different combinations of different ideas. A conceptual design method called the KJ method is very much relevant to the tasks carried out at this stage.

\section{KJ Method for Concept Generation}

KJ method, named after the Japanese anthropologist Jiro Kawakita, establishes an orderly system from a chaos of information [12]. In this method all relevant facts and information are written on individual $4 " \times 5 "$ cards which are collated, shuffled, spread out and read carefully. They are then reviewed, classified, and sorted based on idea similarity, affinity and characteristics. Once the information is sorted under sub-headings, they can be combined to form conceptual designs [10]. The steps in KJ method can be

a) Agree on a topic: The topic should be broad with several facets of views

b) Collect data written on individual cards: Each member of the team collects and writes down several facts, opinions, ideas, one in each card.

c) Scrub and group ideas: Go through the cards one by one explaining the contents to the entire group and group them according to intuition.

d) Title the groups: Now give a succinct title for each group

e) Layout and establish relationships: Establish hierarchies and show the internal relationships among groups

f) Generate concept: Choose different groups and combine them to form sensible concepts meeting the requirements 


\section{Key Characteristic of Entrepreneurship}

The literature in general suggest the following:

a) If, in sympathy with Schumpeterian concept of change, entrepreneurship is considered as fundamentally a gathering and application of existing resources in new ways, successful entrepreneurs are those who are able to gather and combine resources in a unique way that have four essential characteristics: they are rare, they are valuable, they are hard to copy and they are difficult to substitute.

b) Further if an invention is more important it will have a higher probability to establish an enterprise and similarly if it is more radical it will have a higher probability to establish an enterprise.

\section{Aim}

The Aim of this Research can be summarized as 'Development of a systematic methodology for the identification of Entrepreneurial Opportunities'. This should consider the principles of Economic Development, the salient points to be covered under Entrepreneurial opportunity, and the use of knowledge in society. The resulting system can assist to easily identify opportunities that are rare, valuable, hard to copy, difficult to substitute, important and radical.

\section{The Methodology - Trigger}

A Five-step methodology called 'Trigger' is proposed. The first step of it is about choosing a sector in manufacturing. This step is important as this should consider the local situation, the strengths of the graduate, technological opportunities and other similar factors. The second step is aimed at collecting the bits of knowledge dispersed among various people as identified by Hayek [8]. Anything, (facts, opinions, ideas, etc.) in the opinion of the collector is relevant, should be collected and written down, one in each card. If it is a team effort each member should collect the data individually. In the next stage, the cards are taken up one by one explaining the contents to the entire team and grouped as clusters according to intuition. Further cards could be added at this stage as, gaps could be easily identified once the whole picture continues to emerge. Adequacy is an important consideration at this stage. The clusters are given succinct titles in the next step. These titles are written in cards with different color. Now the entire title under consideration is represented by these clusters of cards. If the graduate puts his knowledge components as one additional cluster, the entire knowledge available is visible and placed on the table. Now creative thinking or imagination in combining different subsets could be used to identify different entrepreneurial opportunities. A concept that meets the key characteristics identified earlier could be chosen, as the final 'Entrepreneurial Opportunity' chosen for further development. Figure 1 shows the methodology as a flow chart.
Figure 1: The Trigger Methodology.

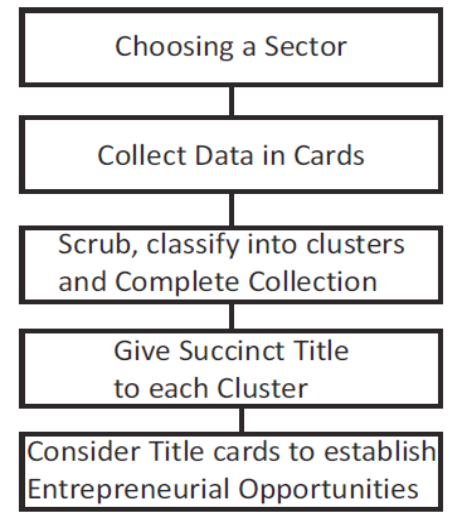

\section{Entrepreneurial Opportunity Using Advanced Water- jet Cutting - Case study}

In this case study the 'Trigger' methodology was used to identify Entrepreneurial Opportunities in waterjet cutting by a group of senior undergraduate students who will become graduates soon.

\section{Choice of the Topic}

The local area has several (literally hundreds) workshops with conventional manufacturing machines and there are practically no CNC machines, excepting few engraving machines for woodwork and laser cutting machines for plastics. The workforce in these workshops are highly skilled and the main works they handle relate to maintenance of heavy vehicles and construction work. There are few state-sponsored advanced manufacturing facilities relating to aircraft, automobile and oil and gas industries, among others. The technology of the country expands and grows in a rapid pace. Thus, there is plenty of scope for small and medium sized manufacturing companies utilizing advanced technologies. The students have concluded that it would be difficult to penetrate the market at skill-centered activities, but they have a good chance of success at advanced knowledge-centered technologies. They identified their theoretical strengths are in mathematics, geometric modelling including graphics and CAD, computer aided manufacturing, design and manufacturing, manufacturing processes and complex machine components and systems. On top of these they had skills in ICT and the training to learn new subjects. The students therefore had the opportunity to choose from the topics

a) a CNC Factory for CNC Machining

b) a CAD, CAM and Simulation Facility for CNC Code Generation

c) a Manufacturing Company for Laser Cutting of Steel and Aluminium Profiles

d) a Manufacturing Company for Waterjet Cutting of Steel 
and Aluminium Profiles

e) a Company for Measurement and Certification of Components for Dimensional Quality

f) Company for Wire Cutting with Electric Discharge Machining for Internal Components

g) A Factory for Steel Fabrication (Welding)

With these in the background they chose waterjet cutting as the sector for their entry.

\section{Collecting Data}

The collected data in a structured format are the results of the next three steps in 'Trigger' methodology. These steps are

a) collecting data in cards

b) scrubbing, classifying and collecting further cards in additionally identified areas and

c) giving a title for each cluster identified during

\section{classification}

Collecting data should be viewed from several different perspectives like what kinds of work could be undertaken, what kind of machines, what kind of inputs from customers, what would be the marketing strategy and the like. A rich collection of data would help identifying better entrepreneurial opportunities and the importance of this step cannot be overemphasized. When a team is engaged in the project the individually collected cards should be discussed and explained to all members. This process is called scrubbing. This process will identify cards or even groups of cards (information) that were being overlooked. Then the cards are classified into clusters where cards relating to the same topic are grouped into a cluster. In the next step after clustering, a heading or a succinct title for each cluster is assigned. For the water jet cutting more than 80 cards were identified by the group. They are classified into 21 clusters as shown in Figure 2. These 21 clusters collectively represent the various knowledge components distributed among the stakeholders.

Figure 2: Classified Data with Identified Cluster Titles.

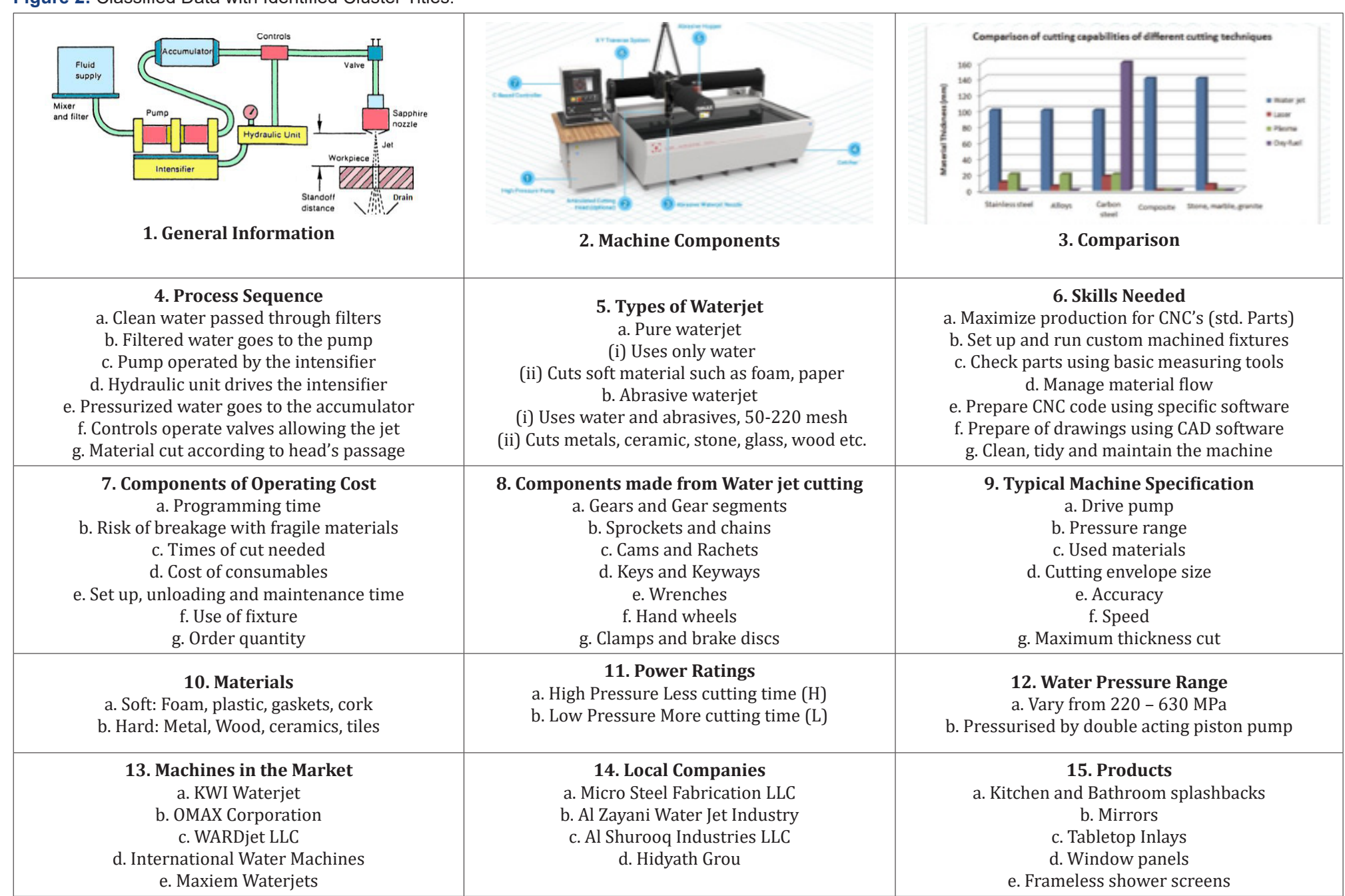




\begin{tabular}{|c|c|c|}
\hline $\begin{array}{c}\text { 16. Target Fields } \\
\text { a. Aerospace } \\
\text { b. Car Industries } \\
\text { c. Gears and Sprocket industries } \\
\text { d. Tile and stone Fabrication } \\
\text { e. Medical inserts }\end{array}$ & $\begin{array}{l}\text { 17. CAD/CAM Software } \\
\text { a. CATIA } \\
\text { b. AutoCAD } \\
\text { c. IntelliMAX }\end{array}$ & $\begin{array}{c}\text { 18. Advantages } \\
\text { a. No heat affected zone } \\
\text { b. No hazardous vapour } \\
\text { c. Stress free cutting } \\
\text { d. High speed cutting of even thick materials } \\
\text { e. No dust, fumes or gases }\end{array}$ \\
\hline $\begin{array}{l}\text { 19. Limitations } \\
\text { a. Limitations in 3D shapes } \\
\text { b. Control of waterjet high speed cutting of circles and } \\
\text { arcs }\end{array}$ & $\begin{array}{l}\text { 20. Types of Companies } \\
\text { a. Job shop making companies in small quantities for } \\
\text { customers' designs } \\
\text { b. Mass production in contract for other companies }\end{array}$ & $\begin{array}{l}\text { 21. Recycling } \\
\text { a. Waste material (scrap) processing } \\
\text { b. Water recycling } \\
\text { c. Abrasive recycling }\end{array}$ \\
\hline
\end{tabular}

\section{Concepts of Entrepreneurial Opportunities}

Concepts of entrepreneurial opportunities are generated by triggering the graduates' interests and inclinations using their theoretical knowledge and the knowledge components in Figure 2. Some concepts are described in the following sub-sections.

\section{High-Tech Water Jet for Medical Inserts}

Medical inserts like the hip joints made in tough materials like Titanium require high precision manufacturing with fine surface finishes. The surfaces of these components are patched free-form surfaces. Thus, computer modelling of the object is fundamental. All the knowledge components the graduate had from his undergraduate study as identified earlier are necessary here.
From the knowledge components identified, general information (1), machine components (2) and process sequence (4) help to understand the process. Cluster number (5) helps to choose the type of waterjet, cluster number (11) helps to choose the required power rating, cluster number (9) helps to define the required machine, clusters (10) and (12) help to choose the materials handled and hence the pressure range, cluster (13) helps the choice of a machine and cluster (14) will tell whether there is a company that has the machine, cluster (17) helps to identify the CAD/CAM software and cluster (20) helps to identify what kind of company could be formulated. Combining these with their theoretical knowledge strengths the students proposed this company. The resulting company is described in Table 1.

Table 1: Identified Entrepreneurial Opportunities.

\begin{tabular}{|c|c|}
\hline Clusters Consulted & Opportunity Description \\
\hline $1,2,4,5,11,9,10,12,13,14,17$. & $\begin{array}{l}\text { High-Tech Water Jet for Medical Inserts - This is a contract manufacturing company serving } \\
\text { medical insert developers with high pressure abrasive water jet cutting. It accepts orders in the } \\
\text { form of CAD models in the IGES or STL format or in the form of DXF drawings in batches of more } \\
\text { than } 10 \text { pieces. Orders can be placed in person or on-line. The company uses advanced five-axis } \\
\text { machine to produce the products resulting high tolerances and surface finish. }\end{array}$ \\
\hline $1,2,4,5,8,12,13,14,20$ & $\begin{array}{c}\text { Precision Water jet Profiles - This is a Job shop for profiling which is a } 2.5 \mathrm{D} \text { activity in hard } \\
\text { materials having several applications such as gears, sprockets, cams and other random profiles. } \\
\text { The enveloping area of the components is limited to } 500 \mathrm{~mm} \times 500 \mathrm{~mm} \text {. Customers can bring their } \\
\text { designs as 2D drawings or files in dxf format. }\end{array}$ \\
\hline 1, 2, 4, 5, 11, 9, 10, 12, 13, 14, 16, 20. & $\begin{array}{l}\text { Water Jet for Stone Sculptures - This is a specialist service company that produces and sells } \\
\text { attractive standard sculptures as well as manufactures for individual customer orders. The cus- } \\
\text { tomers can design their product interactively with the designers in the shop. }\end{array}$ \\
\hline
\end{tabular}

\section{Opportunities Identified}

In a similar fashion the students identified other opportunities shown in Table 1.

'Trigger' is a procedure to provoke the thought process in a systematic way to generate entrepreneurial ideas. These ideas should go through several stages before it results in as the definition of an enterprise. The ideas should go through a market analysis and feasibility study and the concept should be properly scoped and developed as a business plan. Then only it can reach the design, development and launch stages. 


\section{Discussion and Conclusion}

The research is aimed at developing a mechanism to integrate the scientific and technical knowledge the bachelor's degree holding engineer has, with the bits of knowledge spread in the society as identified by Hayek [8]. 'Trigger' is developed as a systematic procedure to integrate these two kinds of knowledge and use the combined chunks of knowledge as a stimulus for generating entrepreneurial ideas. To a great extent it follows the Schumpeterian idea of change as a result of recombining the resources.

The identified entrepreneurial opportunities in Table 1 come from different perspectives. The first one, High-Tech Water Jet for Medical Inserts, is reliant on the quality and capability of the machine and the theoretical or technical competence of the graduate. The idea was triggered by the combination of several of the knowledge chunks identified in the collected data. The second one, Precision water jet profiles, is for providing an advanced technology for the customers. The main advantage the graduate entrepreneur has is his theoretical knowledge. The third one, water jet for stone sculptures, is an innovative idea in using an advanced technology for a new application combining art with advanced theoretical and computer tools. It depends heavily on the theoretical, creative, and business competence of the graduate and the quality and capability of the machine.

The experience suggests that 'Trigger' is a thought-provoking procedure and can lead to the Identification of Entrepreneurial Opportunities in a systematic and easier way.

\section{References}

1. Hicks MJ, Srikant D (2015) The Myth and Reality of Manufacturing in America. Muncie, IN: Ball State University Center for Business and Economic Research.

2. Remarks by President Obama at the Global Entrepreneurship Summit (2015) United Nations Compound, Nairobi, Kenya, July 25.

3. Alin C (2012) A review to a book that is 100 years old. The Theory of Economic Development Schumpeter JA, 1934 (2008). Journal of Comparative Research in Anthropology and Sociology, Winter 3(2).

4. Shane S, Venkataraman S (2000) The promise of entrepreneurship as a field of research. Academy of Management Review 25(1): 217-226.

5. Shane S (2001) Technological Opportunities and New Firm Creation. Management Science 47(2): 205-220.

6. Short JC, Ketchen DJ, Shook CL, Ireland RD (2010) The concept of 'opportunity' in entrepreneurship research: past accomplishments and future challenges. Journal of Management 36(1): 40-65.

7. Per Davidsson (2015) Entrepreneurial opportunities and the entrepreneurship nexus: A re-conceptualization. Journal of Business Venturing 30(5): 674-695.

8. Hayek HA (1945) The Use of Knowledge in Society. The American Economic Review 35(4): 519-530.

9. ABET, 415 North Charles St Baltimore, MD 21201.

10. Irina GS (2014) Professional competences necessary for the bachelor-degree-holding engineer specialising in engineering industries. Pacific Science Review 16(2): 85-88.

11. Niek DP, Louis L A (2019) Framework for Managing the Innovation Process.

12. Karl U (2019) KJ Diagrams.

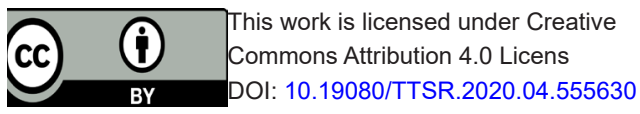

Your next submission with Juniper Publishers will reach you the below assets

- Quality Editorial service

- Swift Peer Review

- Reprints availability

- E-prints Service

- Manuscript Podcast for convenient understanding

- Global attainment for your research

- Manuscript accessibility in different formats

( Pdf, E-pub, Full Text, Audio)

- Unceasing customer service

Track the below URL for one-step submission https://juniperpublishers.com/online-submission.php 